\title{
SYSTEM DYNAMICS SIMULATION MODEL FOR URBAN TRANSPORTATION PLANNING: A CASE STUDY
}

\author{
Suryani, E. ; Hendrawan, R. A. ; Adipraja, P. F. E. ${ }^{* *} \&$ Indraswari, R. ${ }^{* * *}$ \\ * Department of Information Systems, Institut Teknologi Sepuluh Nopember, Surabaya, Indonesia \\ ${ }^{* *}$ STMIK Asia Malang, Indonesia \\ *** Department of Informatics, Institut Teknologi Sepuluh Nopember, Surabaya, Indonesia \\ E-Mail: erma@is.its.ac.id, eraha@is.its.ac.id,philipfaster@asia.ac.id, rarasmaya16@mhs.if.its.ac.id
}

\begin{abstract}
This paper aims to develop an urban transportation planning through the use of system dynamics simulation model. This planning includes congestion mitigation through demand and capacity management, the improvement of public transport sector, and the urban mobility improvement. System dynamics simulation model was used to test and evaluate some alternative policies for urban transportation planning. Simulation results show that mobility depends on travel time, the fulfilment ratio of public transport supply and demand, the effectiveness of public transport transfer distance and transfer time, as well as the access time. Traffic congestion is influenced by the internal factor and external events. This study was conducted at Surabaya, East Java, Indonesia, which is the fourth most congested city in the world. The original scientific contributions of this research include model formulation and development of the daily traffic, urban mobility, and congestion; predictive analysis of the future daily traffic; scenarios development to increase mobility and reduce congestion by considering the internal and external factors.

(Received in August 2019, accepted in December 2019. This paper was with the authors 1 month for 3 revisions.)
\end{abstract}

Key Words: Model, System Dynamics, Urban Transportation Planning, Mobility, Congestion

\section{INTRODUCTION}

An urban area is the centre of business activity, which has complexity and high potential disruption. Common problems in urban areas include transport management and urban mobility [1]: a) traffic congestion and parking management, b) inadequacy of public transport, c) difficulties for non-motorized transport, d) impact of transport sector on the environment and energy consumption, e) traffic accidents and safety. As the population increases, the need for transport infrastructure will increase. It is necessary to transport people and goods quickly, safely, comfortably, and economically. To achieve this goal, problems in the transport system must be identified and carried out [2].

Urban transportation is the main sector in supporting community mobility and freight transportation. It is an important element in economic activity and urban development. High population growth and high levels of urbanization have resulted in an increase in the number of motorized vehicles. According to Rahardjo and Adisasmita, the number of motorized vehicles in Indonesia as a whole increased by $10 \%$ every year, while the construction of new roads is very slow at only $0.05 \%$ per year, thus creating congestion [3]. Traffic congestion occurs in every major city in Indonesia such as Jakarta, Surabaya, Medan, Makassar and others. The data used in this study was obtained from the transportation department of Surabaya city, which has 31 sub-districts. According to a study conducted by Castrol Magnatec Stop-Start Index [4], Surabaya is one of the five largest cities in the world that have the worst congestion. Surabaya ranks fourth most congestion in the world. The majority of Surabaya City's road network system is no longer able to keep up with vehicle volume growth, the ratio of traffic volume to road capacity is about 0.7 [5]. Okraszewska et al. have utilized the integration of a multilevel transport model, they found that cities will soon have to 
rise to the challenge of balancing transport needs and transport behaviour [6]. Therefore, in this research we propose an integrated transportation planning through the use of intelligent mobility modelling. The questions that guided this research were:

1. What is the drivers' influence toward the mobility of transportation systems?

2. How do these drivers dynamically interact to influence the daily traffic and congestion?

3. How to project the daily traffic in the future by considering the internal and external factors?

4. What strategies should be done in improving mobility performance and reducing traffic congestion?

To answer these research questions and accomplish the modelling objectives, system dynamics modelling is used because of the easy-to-use interface and the availability of facilities that can provide long-term experience. This study can provide new insight and knowledge in developing an integrated transportation planning by incorporating there key aspects to integration such as: 1) integrating public transport fulfilment ratio, travel time, the effectiveness of transfer and access time, and urban mobility; 2) integrating the urban mobility and daily traffic; 3 ) integrating the daily traffic, external events, and congestion. The original scientific contributions of this research include: model formulation and development of the daily traffic, urban mobility, and congestion; predictive analysis of the future daily traffic; scenarios development to increase mobility and reduce congestion by considering the internal and external factors. This paper is organized as follows. Section 2 demonstrates the literature review consisting of intelligent mobility modelling and integrated transportation planning. Section 3 explains the method use (system dynamics). Section 4 demonstrates base model development. Section 5 provides model validation. Scenario development has been explained in Section 6. Results and discussion have been demonstrated in Section 7. Finally, in Section 8, conclusion and further research required are presented.

\section{LITERATURE REVIEW}

Urban transportation planning aims to develop an integrated transportation planning that can provide an effective decision support system tool for urban planning and promote the use of public transport systems in urban areas. Integrated transportation planning model can provide an effective decision support system tool for urban planning [7].

\subsection{Urban transportation planning}

Transportation system plays an important role in transportation supply, urban economic growth, settlement structure, and social environment. City structure is one of the factors that influence urban mobility [7]. Integrated transportation planning has three main components as follows:

a. Outcomes that represents the objective of the transportation system.

b. Principles that will guide the development of transportation system options.

c. Planning process that provides a systematic approach for transportation planning.

Transportation planning process includes a number of steps as described below:

- Monitoring the existing conditions of transportation systems;

- Forecasting the future population and identifying the major growth corridors;

- Identifying and analysing current and projected future transportation problems and needs through various transportation improvement strategies to address those needs;

- Developing long-range plans and short-range programs of several alternative improvements;

- Estimating the impact of several future improvements to the transportation systems. 


\subsection{Intelligent mobility modelling}

Urban transportation policy planning usually focuses on sustainable urban mobility that can be supported by using intelligent mobility modelling. Intelligent Mobility explores new and different ways to improve the efficiency of people and goods movements, thus requiring the integration of some sectors. A platform for providing a comprehensive planning and evaluation is a simulation modelling and analysis that can facilitate the projection of future planning results [8]. Simulations have been growing in many domains due to several benefits:

- Allow representation of a real life situation through several experiments.

- Explicitly represents the process of modelling and their interactions among variables.

- Facilitate interactive models to analyse the existing system and developed some strategies.

- Support the projection of potential future conditions.

Simulation allows controlling the relevant variables, running multiple scenarios and experiments in Intelligent Transportation Systems [9]. A more qualitative analysis frameworks require an inclusive modelling and simulation platform [10]. In simulation, the system performance can be observed under different sets of parameters which can be easily changed [11]. Gong et al. have established one resource scheduling simulation model that can assess the effects of the number of service workers and the charging pile maintenance times on charging station revenues [12]. Hartmann et al. have utilized optimization models to optimize the passenger waiting time at the station and to meet the requirements of companies [13]. Rajsman et al. have analysed the absolute and relative structure of transport relations according to the established categories in the Croatian road freight transport [14].

\section{METHOD}

There are several modelling approaches that can be used such as microsimulation and system dynamics. Microsimulation is used to estimate how demographic, behavioural, and policy. The model uses information at the level of microeconomic individual agents such as individuals, households, firms [15]. It has some disadvantages such as: 1) system behaviour is not modelled, 2) results in sequential application may depend on the order in which the sequence of agent parameter changes.

In this study, system dynamics is used as a method to develop the urban transportation planning based on consideration that system theory and system dynamics modelling can study comprehensively and dynamically from transportation systems such as road transportation networks, vehicle growth, fuel consumption and carbon emissions [16]. Del Vecchio et al. have utilized system dynamics to evaluate six scenarios corresponding to the different solutions available for particular segments of demand [17]. Marshall has utilized system dynamics to analyse the impact of Internet of Things on intelligent urban transportation [18]. To develop system dynamics simulation model, several steps are required as follows [19]: 1) Problem formulation, 2) Dynamics hypothesis, 3) Model formulation, 4) Testing, 5) Policy formulation and evaluation.

\section{BASE MODEL DEVELOPMENT}

To provide an integrated transportation planning, we developed model simulation to learn the transportation system behaviour that has significant impact on mobility performance, daily traffic, and congestion as well as to evaluate several alternatives to improve transportation system performance. Modelling involves the use of mathematical expressions and data to design, build, and manage planning tools [8]. There are three key aspects to integration: 
1. integrating public transport fulfilment ratio, travel time, the effectiveness of transfer and access time, and urban mobility,

2. integrating the urban mobility and daily traffic,

3. integrating the daily traffic, external events, and congestion.

\subsection{Problem formulation}

In this step, we need to determine the model boundaries, variables, and data requirement. Model boundary involves selecting components necessary to generate the behaviour of interest related to the model purpose [20]. Travel time demand and distance are the main factors of the choice of transportation mode [21]. Some of the other factors that influence congestion include external events, daily traffic, and internal factors [22, 23]. Traffic control such as transferring traffic flow also affects external events; it can be done by utilizing Information and Communication Technology (ICT) that helps in planning and managing traffic $[24,25]$. Congestion is also influenced by internal factors, such as road capacity and daily traffic [26]. Integrated planning of transportation system encompasses of regional accessibility, connectivity, roadway design, parking management, transit accessibility, site design, mobility management [27].

\subsection{Dynamic hypothesis and model development}

a. Causal loop diagram development

Causal loop diagram (CLD) development is the basic framework used in developing system dynamics simulation model. CLD of daily traffic volume, traffic congestion, and mobility performance can be seen in Fig. 1.

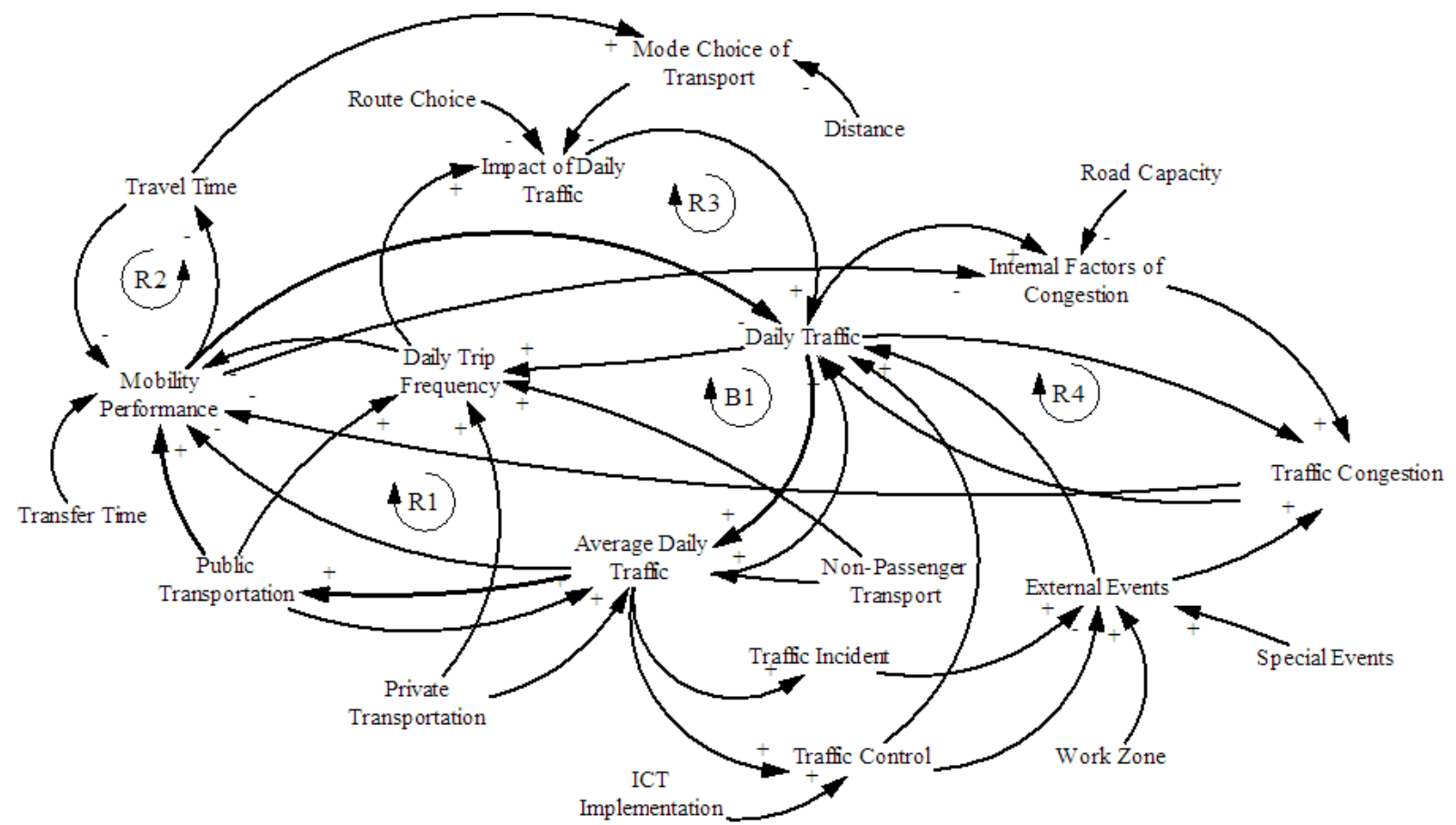

Figure 1: CLD of daily traffic volume, traffic congestion, and mobility performance.

This CLD is developed by referring to the problem formulation. Several factors affecting traffic congestion include internal factors and external events [22, 23]. Congestion is caused by excess vehicles on the highway [28]. Some techniques to reduce traffic congestion [29], such as: a) providing exclusive lanes; b) using information technology for traffic control. Daily traffic and road capacity are two internal factors that have significant impact on traffic 
congestion [25-27]. Mobility depends on several factors such as travel time, daily trip frequency, transfer time, and the number of public transportation [21, 26]. Average daily traffic and ICT implementation will influence the traffic control; hence it can manage the daily traffic [24]. Traffic control can be done by utilizing ICT that helps in planning and managing traffic $[24,25]$.

b. Stock and flow diagram (SFD) development

In this step, all variables must be defined and assigned with the correct units, and mostly new variables must be added to the SFD [30].

b1. Mobility performance

The SFD of mobility performance and public transportation fulfilment ratio can be seen in Fig. 2. As we can see from Fig. 2, mobility performance depends on travel time performance, the ratio of fulfilment (demand and public transportation supply), the effectiveness of public transport (PT) transfer distance and transfer time, as well as the access time. Travel time performance is a comparison of the average private car travel time and the average of public transport travel time. The effectiveness of public transport (PT) transfer distance is a comparison of the maximum effective walking distance and the walking distance. The effectiveness of public transport transfer time is influenced by the maximum transfer Time and the average transfer time. Meanwhile, access time is a comparison of the fastest access time and the average access time of public transport. Model formulation of mobility performance is described in Eqs. (1) to (8).

$$
\begin{aligned}
& \text { Mobility Performance }(t)=\frac{\text { PT Supply }(t)}{\text { PT Demand }(t)}+\frac{\text { Max. Eff. Walking Distance }(t)}{\text { Transfer Walking Distance }(t)} \\
& +\frac{\text { Maximum Transfer Time }(t)}{\text { Average Transfer Time }(t)}+\frac{\text { Fastest PT Access Time }(t)}{\text { Average PT Access Time }(t)} \\
& +\frac{\text { Private Cars Travel Time }(t)}{\text { PT Travel Time }(t)} \\
& \text { Population }(t)=\int_{t 0}^{t} \text { Population Growth }(t)+\text { Initial Population } \\
& \text { * Percentage of PT Demand }(t) \\
& \text { PT Fulfillment Ratio }(t)=\frac{\sum \text { Public Transportation Supply }(t)}{\text { Public Transportation Demand }(t)} \\
& \text { Travel Time Performance of PT }(t)=\frac{\text { Average Private Cars Travel Time }(t)}{\text { Average Public Transportation Travel Time }(t)} \\
& \text { Effectiveness of Transfer Distance }(t)=\frac{\text { Maximum Effective Walking Distance }(t)}{\text { Transfer Walking Distance }(t)} \\
& \text { Effectiveness of Transfer Time }(t)=\frac{\text { Maximum Transfer Time }(t)}{\text { Average Transfer Time }(t)} \\
& \text { Effectiveness of Access Time }(t)=\frac{\text { Fastest Access Time }(t)}{\text { Average Access Time }(t)}
\end{aligned}
$$

b2. Average daily traffic

We could categorize the average daily traffic into three classes: non-passenger, public transportation, private and share transportation. The model formulation of daily traffic $(D T)$ volume is described in Eqs. (9) and (10). 


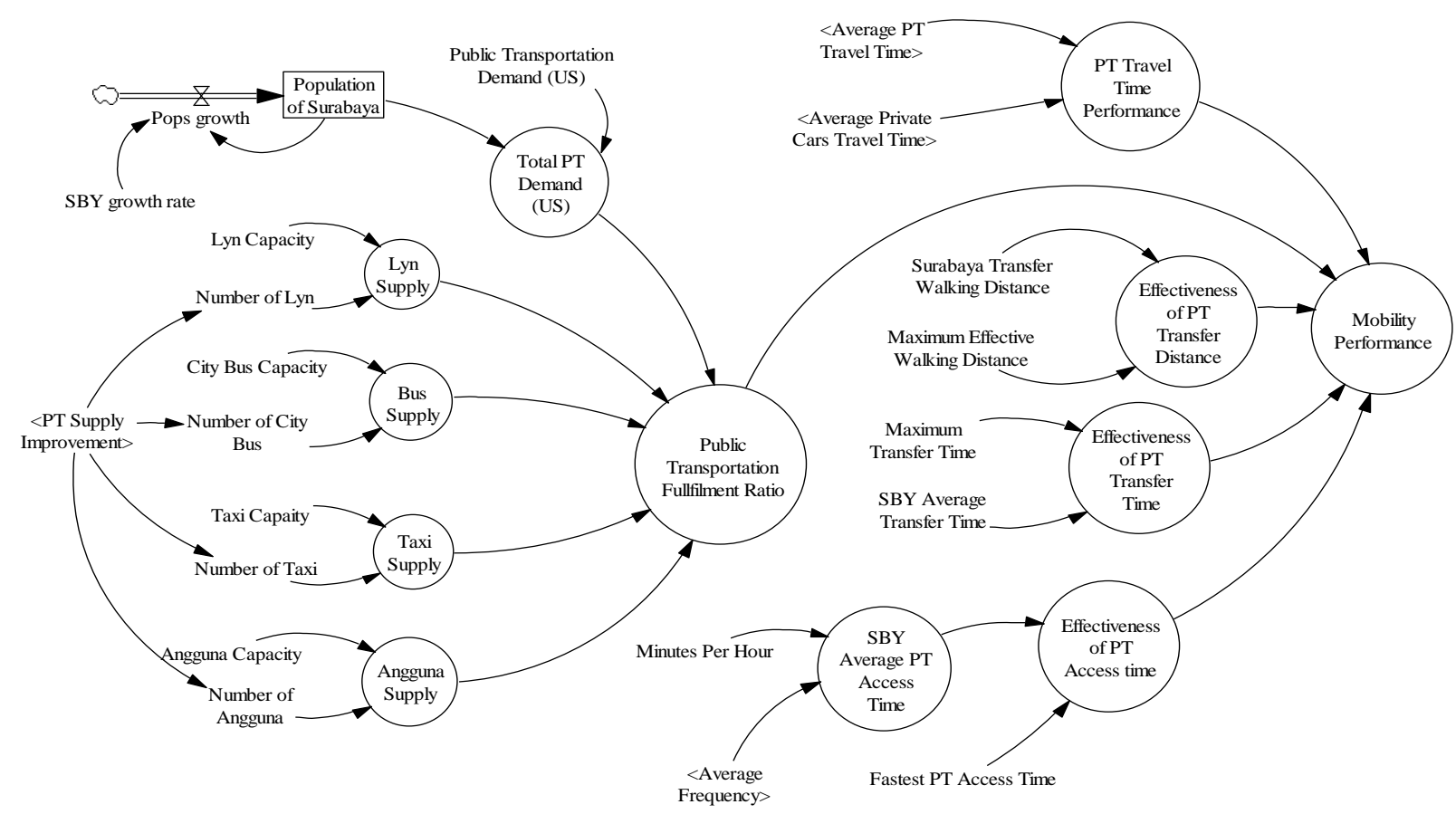

Figure 2: SFD of mobility performance.

Daily Traffic $(t)=\frac{1}{100}($ SMOOTH31 $(D T(t)-$ Average $D T(t)$, Slack Time, Initial Traffic

$$
\text { - Average } D T) * D T \text { Impact }(t))
$$

The rate of the expected value of daily traffic $(t)=\frac{\bar{A}-A}{\tau}$

where: $\bar{A}$ - actual value of daily traffic,

$A$ - expected value of daily traffic,

$\tau$-adjustment time.

b3. Traffic congestion

Several driver of Congestion can be seen in Fig. 3. SFD of traffic congestion can be seen in Fig. 4. Congestion is influenced by the internal factor (such as daily traffic and road capacity) and external events such as special events, work zones, traffic incidents, and poor traffic control. The model formulation of congestion is depicted in Eqs. (11) and (12).

$$
\text { Internal Factor of Congestion Driven }(t)=\frac{\text { Average Hourly Traffic }(t)}{\text { Road Capacity }(t)}
$$

Traffic Congestion $(t)=($ Internal Factor of Congestion Driven $(t)$

$$
\begin{aligned}
& \left.* \frac{\text { Congestion Weight }(t)}{100}\right)+\left(\frac{\text { External Events }(t)}{100}\right. \\
& * \text { Internal Factor of Congestion Driven }(t))
\end{aligned}
$$

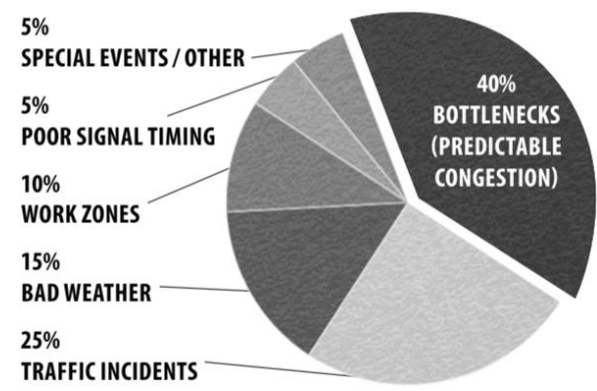

Figure 3: Several drivers of traffic congestion [31]. 


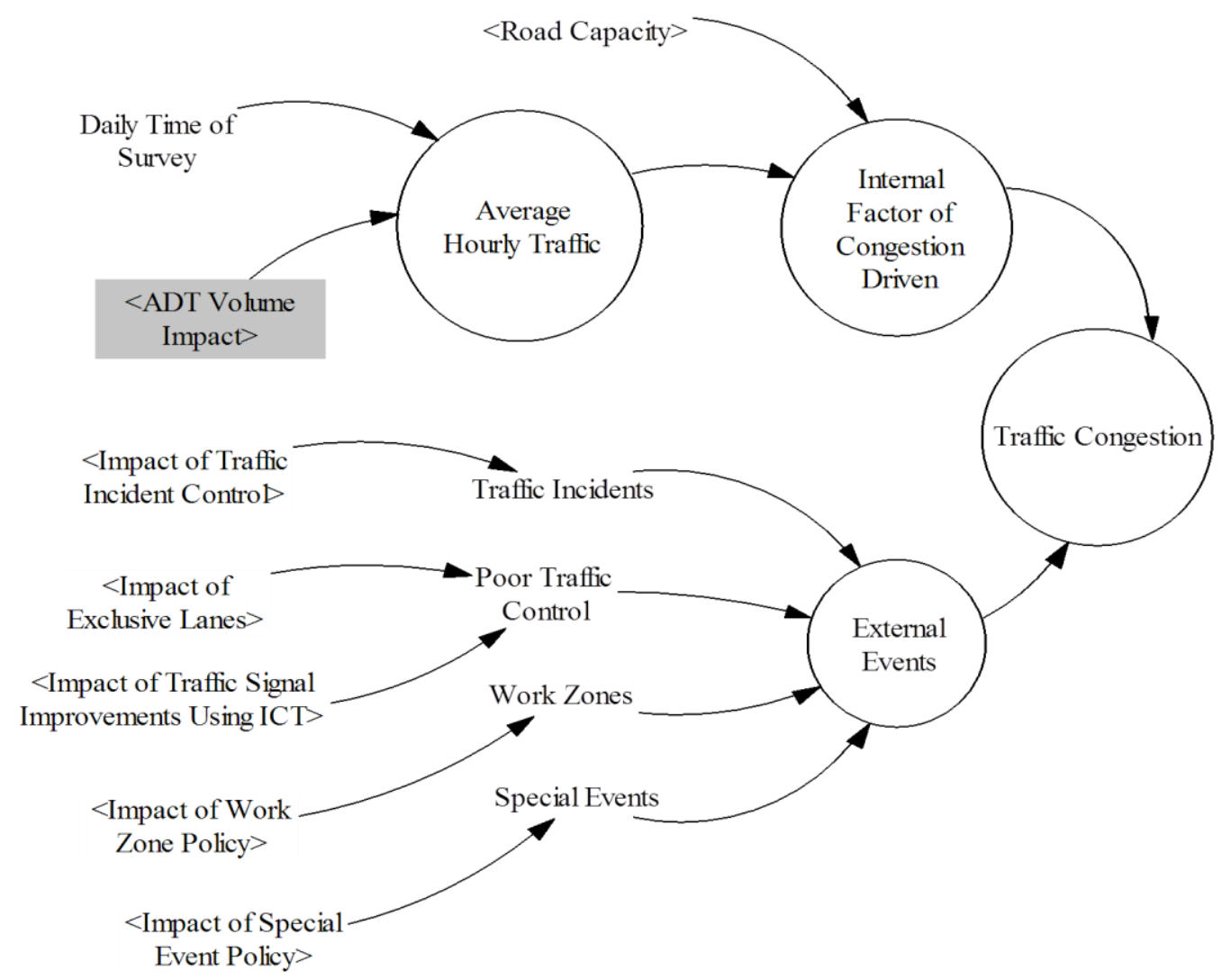

Figure 4: SFD of traffic congestion.

\section{MODEL VALIDATION}

Model validation is required to check the model validity. In this step, we need to compare between simulation model and historical data. We utilized historical data of daily traffic and city population in 2000-2017 from Transportation Department of Surabaya. According to Barlas, a model will be valid if the error rate is $\leq 5 \%$ and the error variance is $\leq 30 \%$ [32]. Error rate is a comparison of the difference between the average of the model and the average of the data, and the average of the data. Error variance is a comparison of the difference between the standard deviation of the model and the standard deviation of data, and the standard deviation of the data. Error rate of some variables of daily traffic volume in several roads and population are as follows:

Error rate "daily traffic volume in Wonokromo road" $=\frac{|434,912-425,968|}{425,968}=0.021$

Error rate "daily traffic volume in Ahmad Yani road" $=\frac{|381,172-363,339|}{363,339}=0.05$

Error rate "population" $=\frac{|2,745,283-2,748,525|}{2,748,525}=0.0012$

Meanwhile, the error variance of some variables of daily traffic volume in several roads and population are as follows:

Error variance "daily traffic volume in Wonokromo road" $=\frac{|65,367-89,009|}{89,009}=0.26$

Error variance "daily traffic volume in Ahmad Yani road" $=\frac{|76,045-74,095|}{74,095}=0.03$

Error variance "population" $=\frac{|46,415-46,606|}{46,606}=0.0041$ 


\section{SCENARIO DEVELOPMENT FOR INTEGRATED TRANSPORTATION PLANNING}

Scenario planning is an assumption of what will happen in the future [33]. Some alternative scenarios can be done by changing the model structure and parameters [34]. Several scenarios for integrated transportation planning are used to articulate and evaluate several strategies for the future of urban mobility and congestion. This integrated transportation planning consists of three key aspects: 1) scenario to mitigate congestion through demand and capacity management; 2) scenario for congestion mitigation with the improvement of public transportation sector; 3) scenario to improve mobility performance.

\subsection{Mitigating congestion through demand and capacity management}

Road capacity improvement can be conducted through cross road improvement and the development of new roads. Demand management is a program to manage travel demand through parking policy, road routing, area and cordon licensing, and physical limitation.

\subsection{Mitigating congestion with the improvement of public transportation sector}

Congestion mitigation can be done by increasing the interest in the use of public transportation.

Several strategies can be undertaken such as providing affordable public transport fares (public cost impact), improving safety (PT safety impact), improving service reliability (PT reliability impact) and comfort (PT comfort impact) of the transport sector.

\subsection{Improving mobility performance}

Increasing mobility performance can be done through the improvement of public transport travel time, the effectiveness of transfer and access time, as well as the increased of public transport fulfilment ratio.

\section{RESULTS AND DISCUSSION}

In this study we use Surabaya as a case study, because Surabaya is the fourth most congested city in the world [4]. Although this study is a case study, we make the model as generic as possible, so if this model will be used for a case study in elsewhere, the model can be used by adjusting the parameter values of the model to match the place where the case study will be conducted.

\subsection{Mobility performance}

Mobility performance can be measured from travel time, the ratio of public transportation fulfilment, the effectiveness of transfer distance and transfer time, and the access time. The simulation result of mobility performance based on the existing condition is shown in Fig. 5 . Mobility performance tends to decline from $70 \%$ in the year of 2000 to $67.3 \%$ in the year of 2017. This is due to the decreased of public transportation fulfilment ratio, travel time, the effectiveness of transfer time, and the effectiveness of transfer distance and access time. 


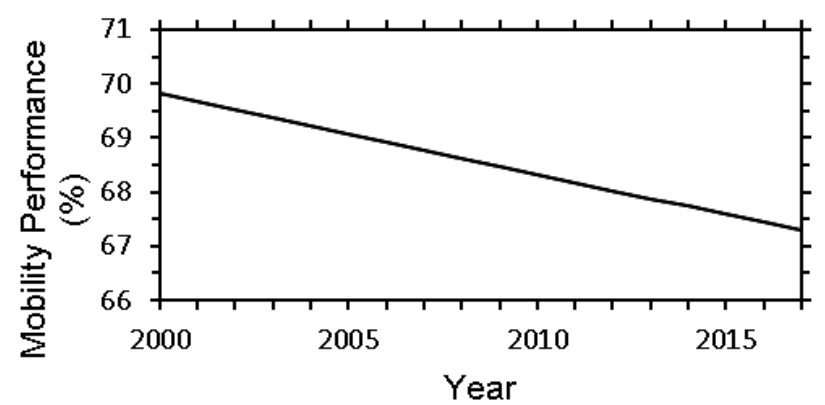

Figure 5: Mobility performance based on the existing condition.

\subsection{Traffic congestion}

Simulation result of traffic congestion can be seen in Fig. 6. As we can see from Fig. 6, traffic congestion exceeds $100 \%$ starting from 2009, this is due to external events (special events, work zones, poor traffic control, and traffic incidents) and the internal factor such as the hourly traffic and road capacity. Several research results stated that typically recommended a fixed degree of traffic saturation is around $85 \%$ [35].

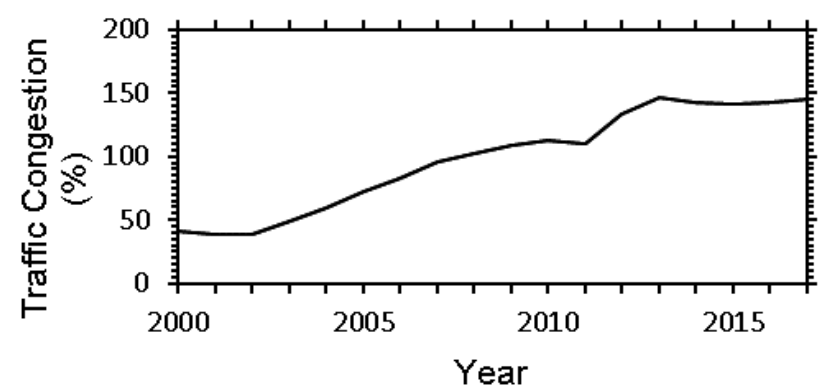

Figure 6: Traffic congestion based on the existing condition.

\subsection{Scenario results of congestion mitigation through demand and capacity management}

In this research, we set the simulation time frame for 20 years based on the consideration that the assets of the road and transportation network infrastructure are long-term assets.

We assumed that in the next 20 years: 1) there will be an increase in road capacity by $25 \%$ based on historical data on increasing road network capacity, 2) there will be an increase in the use of public transportation by presenting convenient and fast transportation. Fig. 7 represents the scenario results of congestion mitigation through demand and capacity management. Congestion can be decreased to $61 \%$ - $70 \%$, due to the decreased in internal factor of congestion driven and the decrease in the impact of external events. The decrease in the external events can be done through ICT implementation for traffic and route controls. The decrease in the internal factor of congestion driven can be achieved through demand management by providing parking policy, road routing, and physical limitation.

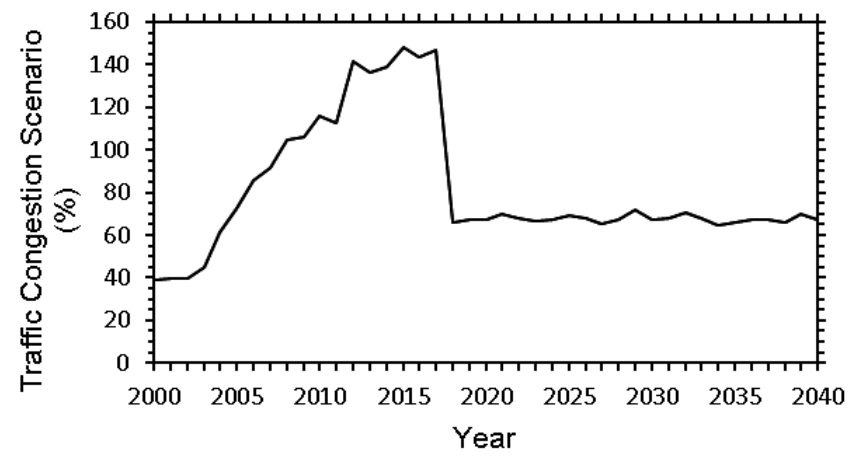

Figure 7: Traffic congestion scenario through demand and capacity management. 


\subsection{Scenario results of improving mobility performance}

Simulation result of scenario planning to improve mobility performance can be seen in Fig. 8 . Mobility performance is projected would be increased by $7 \%$ due to the increase of the effectiveness of access time and travel time performance. The increase of the effectiveness of access time can be achieved through faster access time. An increase in access time speed by $33.3 \%$ resulted in an increase in effectiveness by $50 \%$. The increase of travel time performance can be achieved through faster travel time. A $19 \%$ reduction in travel time resulted in an increase in travel time performance of $16.42 \%$.

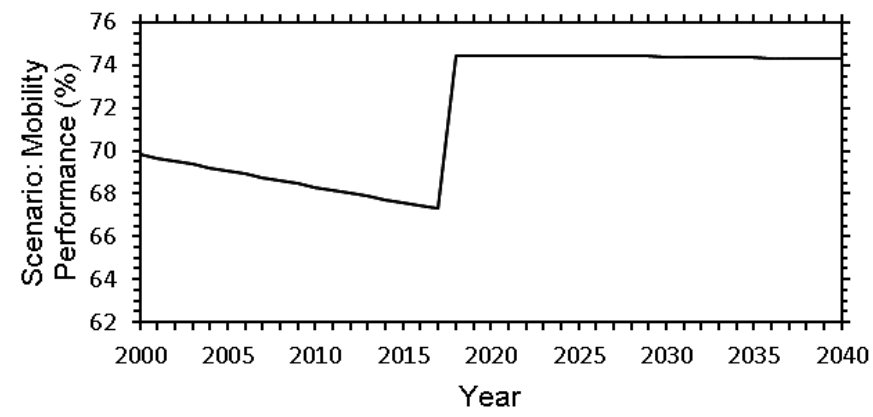

Figure 8: Mobility performance scenario.

\section{CONCLUSION AND FURTHER RESEARCH}

The purpose of this paper is to test and evaluate some future alternatives to improve the performance of transportation systems through intelligent mobility modelling. By applying the intelligent mobility modelling, some alternatives strategies can be tested and evaluated to mitigate congestion and improve mobility Congestion mitigation can be done through demand and capacity management as well as the use of ICT for traffic and route controls.

This study is designed to make a novel contribution in urban transportation planning using system dynamics simulation model. The causal relationship among variables in the CLD, converting the CLD into the SFD, and developing several scenarios would be the novel contributions in terms of the urban mobility modelling. This paper contributes to the literature by theoretically and empirically investigating such relationships through the use of model and scenarios planning.

Mobility performance depends on travel time performance, the fulfilment ratio of public transport supply and demand, the effectiveness of public transport (PT) transfer distance and transfer time, as well as the access time. Meanwhile, congestion is determined by two factors, those are internal and external factors. Mobility performance is projected would be increased by $7 \%$ due to the increase of the effectiveness of access time and travel time performance. Congestion can be decreased to $61 \%-70 \%$ by implementing ICT for route and traffic controls as well as managing demand and capacity of transport network (e.g. parking policy, road routing, area and cordon licensing, physical limitation, exclusive lanes, work zone policies for safety and mobility, special event management, road capacity improvement to enhance the road capacity as the traffic demand increases). Further research is required to improve the operational efficiency and safety of transportation systems as well as to develop a financial plan for obtaining sufficient revenues to cover the costs of several implementing strategies.

\section{ACKNOWLEDGEMENT}

This work is supported by ITS (Institut Teknologi Sepuluh Nopember) Research Center, Transportation Department of Surabaya City, and Enterprise Systems Laboratory. 


\section{REFERENCES}

[1] Rodrigue, J.-P.; Comtois, C.; Slack, B. (2017). The Geography of Transport Systems, $4^{\text {th }}$ edition, Routledge, New York

[2] Maršanić, R.; Krpan, L. (2015). Contemporary issues of urban mobility, International Journal Vallis Aurea, Vol. 1, No. 2, 5-14, doi:10.2507.IJVA.1.2.1.12

[3] Rahardjo, A.; Adisasmita, S. A. (2011). Manajemen Transportasi Darat, Graha Ilmu, Yogyakarta

[4] Pantazi, C. (THRILLIST - Travel) (2015). The Worst Traffic in the World is in ..., from https://www.thrillist.com/travel/nation/city-with-worst-traffic-jakarta-indonesia-tops-castrol-sranking-of-cities-with-most-stop-starts, accessed on 19-07-2019

[5] Surabaya City Government. Rencana Pembangunan Jangka Menengah Daerah Kota Surabaya Tahun 2010-2015, from https://surabaya.go.id/uploads/attachments/files/doc_762.pdf, accessed on 09-08-2019

[6] Okraszewska, R.; Romanowska, A.; Wołek, M.; Oskarbski, J.; Birr, K.; Jamroz, K. (2018). Integration of a multilevel transport system model into sustainable urban mobility planning, Sustainability, Vol. 10, No. 2, Paper 479, 20 pages, doi:10.3390/su10020479

[7] Brandi, A.; Gori, S.; Nigro, M.; Petrelli, M. (2014). Development of an integrated transport-land use model for the activities relocation in urban areas, Transportation Research Procedia, Vol. 3, 374-383, doi:10.1016/j.trpro.2014.10.018

[8] Neffendorf, H.; Fletcher, G.; North, R.; Worsley, T.; Bradley, R. (Transport Systems Catapult). (2015). Modelling for Intelligent Mobility, from https://ts.catapult.org.uk/wpcontent/uploads/2016/04/Modelling-Intelligent-Mobility-Feb-2015.pdf, accessed on 15-03-2019

[9] Fernández-Isabel, A.; Fuentes-Fernández, R. (2015). Analysis of intelligent transportation systems using model-driven simulations, Sensors, Vol. 15, No. 6, 14116-14141, doi: $10.3390 / \mathrm{s} 150614116$

[10] Ramos, A. L.; Ferreira, J. V.; Barceló, J. (2012). Modeling \& simulation for intelligent transportation systems, International Journal of Modeling and Optimization, Vol. 2, No. 3, $274-$ 279, doi: $10.7763 /$ IJMO.2012.V2.126

[11] Gocken, T.; Dosdogru, A. T.; Boru, A.; Gocken, M. (2019). Integrating process plan and part routing using optimization via simulation approach, International Journal of Simulation Modelling, Vol. 18, No. 2, 254-266, doi:10.2507/IJSIMM18(2)470

[12] Gong, D.; Tang, M.; Liu, S.; Xue, G.; Wang, L. (2019). Achieving sustainable transport through resource scheduling: A case study for electric vehicle charging stations, Advances in Production Engineering \& Management, Vol. 14, No. 1, 65-79, doi:10.14743/apem2019.1.312

[13] Hartmann Tolić, I.; Martinović, G.; Crnjac Milić, D. (2018). Optimization methods in modern transportation systems, Technical Gazette, Vol. 25, No. 2, 627-634, doi:10.17559/TV20170326212717

[14] Rajsman, M.; Luburić, G.; Muhin, M. (2017). Dynamics and trends of the development of transport relations in road freight transport, Technical Gazette, Vol. 24, No. 2, 635-642, doi:10.17559/TV-20151222091742

[15] Sánchez, V. M.; Cicowiez, M. (2012). Microsimulation approach. Presentation for the Second intensive training workshop on Strengthening Macro-Micro Modelling Capacities to Assess Development Support Measures and Strategies, from https://www.un.org/en/development/desa/ policy/capacity/presentations/ecuador2/10-microsimulation-approach.pdf, accessed on 18-032019

[16] Rawal, T.; Devadas, V. (2015). System dynamics modeling for transportation planning in Kanyakumari district, Tamil Nadu, Proceedings of the 2015 Conference on System Dynamics Society of India, 1-26

[17] Del Vecchio, P.; Secundo, G.; Maruccia, Y.; Passiante, G. (2019). A system dynamic approach for the smart mobility of people: Implications in the age of big data, Technological Forecasting and Social Change, Vol. 149, Paper 119771, doi:10.1016/j.techfore.2019.119771

[18] Marshall, P. (2015). System dynamics modeling of the impact of internet-of-things on intelligent urban transportation, Proceedings of the 2015 Regional Conference of the International Telecommunications Society, Paper 56, 10 pages 
[19] Sterman, J. D. (2000). Business Dynamics: Systems Thinking and Modeling for a Complex World, Irwin/McGraw-Hill, Boston

[20] Albin, S.; Forrester, J. W.; Breierova, L. (2001). Building a System Dynamics Model: Part 1: Conceptualization, Massachusetts Institute of Technology, Cambridge

[21] Bastarianto, F. F.; Irawan, M. Z.; Choudhury, C.; Palma, D.; Muthohar, I. (2019). A tour-based mode choice model for commuters in Indonesia, Sustainability, Vol. 11, No. 3, Paper 788, 20 pages, doi: $10.3390 / \mathrm{su} 11030788$

[22] Das, D.; Keetse, M. (2015). Assessment of traffic congestion in the central areas (CBD) of South African cities: A case study of Kimberly city, Proceedings of the $34^{\text {th }}$ Annual Southern African Transport Conference, 835-850

[23] Suryani, E.; Hendrawan, R. A.; Adipraja, P. F. E.; Dewi, L. P. (2018). Congestion mitigation scenario through public transportation improvement, Proceedings of the $3^{\text {rd }}$ International Conference on Electrical Systems, Technology and Information, Paper 01008, 10 pages, doi: $10.1051 /$ matecconf $/ 201816401008$

[24] Calafate, C. T.; Soler, D.; Cano, J.-C.; Manzoni, P. (2015). Traffic management as a service: The traffic flow pattern classification problem, Mathematical Problems in Engineering, Vol. 2015, Paper 716598, 14 pages, doi: $10.1155 / 2015 / 716598$

[25] Fanti, M. P. (2011). ICT application on the management of intelligent transportation systems, Cetto, J. A.; Filipe, J.; Ferrier, J. L. (Eds.), Informatics in Control Automation and Robotics: Lecture Notes in Electrical Engineering, Vol. 85, Springer, Berlin, 3-13, doi:10.1007/978-3-64219730-7_1

[26] Mudiyono, R. (2017). Bus rapid transit (BRT) operations to reduce traffic congestion on Kaligawe road in Semarang, Proceedings of the 2017 International Conference on Coastal and Delta Areas, 768-774

[27] Litman, T. (2003). The online TDM Encyclopedia: mobility management information gateway, Transport Policy, Vol. 10, No. 3, 245-249, doi:10.1016/S0967-070X(03)00025-8

[28] Cambridge Systematics, Inc. with Texas T. I. (2005). Traffic Congestion and Reliability: Trends and Advanced Strategies for Congestion Mitigation (Final Report, 140 pages), from https://ops.fhwa.dot.gov/congestion_report/congestion_report_05.pdf, accessed on 19-08-2019

[29] Nash, A. Reduce Traffic Congestion, from http://crowdsourced-transport.com/workingpages/improve-public-transport/reduce-traffic-congestion/, accessed on 19-08-2019

[30] Aronson, D.; Angelakis, D. Step-By-Step Stocks and Flows: Converting from Causal Loop Diagrams, from https://thesystemsthinker.com/step-by-step-stocks-and-flows-converting-fromcausal-loop-diagrams, accessed on 25-09-2018

[31] Oregon Department of Transportation. Improving highway bottlenecks: addressing congestion around the Portland metro area, from https://www.oregon.gov/ODOT/Projects/Project \%20Documents/CBOS-Fact-Sheet-18836.pdf, accessed on 25-09-2018

[32] Barlas, Y. (1996). Formal aspects of model validity and validation in system dynamics, System Dynamics Review, Vol. 12, No. 3, 183-210, doi:10.1002/(SICI)1099-1727(199623)12:3<183: :AID-SDR103>3.0.CO;2-4

[33] Mariton, J. Strategic Planning and Management Insights: What is Scenario Planning and How to Use it, from https://www.smestrategy.net/blog/what-is-scenario-planning-and-how-to-use-it, accessed on 19-08-2019

[34] Suryani, E.; Chou, S.-Y.; Chen, C.-H. (2012). Dynamic simulation model of air cargo demand forecast and terminal capacity planning, Simulation Modelling Practice and Theory, Vol. 28, 27 41, doi:10.1016/j.simpat.2012.05.012

[35] Hale, D.; Courage, K. G. (2002). Prediction of traffic-actuated phase times on arterial streets, Transportation Research Record, Vol. 1811, No. 1, 84-91, doi:10.3141/1811-10 